\title{
Snack frequency: associations with healthy and unhealthy food choices
}

\author{
Christina Hartmann*, Michael Siegrist and Klazine van der Horstt \\ ETH Zurich, Institute for Environmental Decisions (IED), Consumer Behaviour, Universitätstrasse 22, $\mathrm{CH}-8092$ \\ Zurich, Switzerland
}

Submitted 23 September 2011: Final revision received 28 June 2012: Accepted 3 July 2012: First published online 16 August 2012

\begin{abstract}
Objective: We examined associations between snack frequency, sociodemographic characteristics, BMI, dietary and eating behaviour. In order to identify whether various subgroups of high-frequency snack consumers exist, we investigated underlying food patterns and lifestyle factors.

Design: The data were based on the Swiss Food Panel Questionnaire of 2010, which included an FFQ, questions relating to sociodemographics and lifestyle factors. Data were examined using ANOVA, regression analysis and hierarchical cluster analysis. Gender differences were also investigated in the analysis of the data.

Setting: A sample of 6189 adults participating in the Swiss Food Panel filled in a questionnaire (response rate 30\%).

Subjects: The sample consisted of both men and women, with a mean age of $54 \cdot 4(\mathrm{SD} 13 \cdot 5)$ years.

Results: There was no association between snack frequency and BMI. Consumption frequency of sweets and savouries as well as fruit intake increased with increasing snack frequency. Additionally, three different subgroups of high-frequency snack consumers could be revealed: healthy, moderate and unhealthy dietary-pattern groups. The latter included respondents who were less health-conscious and was characterized by high alcohol consumption frequency, daily breakfast skipping and watching television during the main meal.

Conclusions: High snack frequency occurred in the context of healthy as well as unhealthy dietary behaviour and lifestyle patterns. Women made healthier dietary food choices and were more likely to consume fruits as snacks, while men chose unhealthy foods, such as sweets and savouries, more often.
\end{abstract}

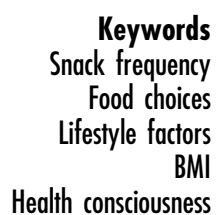

Eating frequency is affected by cultural/social norms, lifestyle factors, the environment and an individual's personal attitudes towards his/her health ${ }^{(1,2)}$. Changes in lifestyle and the environment over the last few decades have probably been the most important causes of the overweight epidemic in Western society ${ }^{(3)}$. The increasing proportion of snacking in the Western diet has been a particular cause for concern, since the foods and drinks typically consumed as snacks tend to be energy-dense ${ }^{(4)}$. In the scientific literature, no consensus exists about whether a higher frequency of eating, and particularly snacking, promotes or prevents weight gain ${ }^{(5,6)}$.

In spite of an unclear association with body weight, snacking per se does not have a negative effect on diet quality. Snacking can increase the opportunity for healthy, low-energy food choices, resulting in a wider variety of foods in the diet and a balanced intake of

$\dagger$ Present address: Food Consumer Interaction, Nestlé Research Center, PO Box 44, 100 Lausanne 26, Switzerland. nutrients contributing significantly to daily micro- and macronutrient intakes ${ }^{(7-9)}$.

An important issue related to snack frequency is whether energy intake from snacks between meals will be compensated for by a lower energy intake from the main meals, because a higher number of eating occasions seems not to be associated with an improvement in appetite control and provides more opportunities to consume excess energy ${ }^{(10)}$. Nevertheless, meal skipping, especially breakfast skipping, is associated with overeating later in the day, due to intense hunger followed by ingestion of high-fat, sugar-dense snacks ${ }^{(11)}$.

Overweight and obesity status was found to be associated with higher intakes of fat, refined grains, red meat, added sugars and sugar-sweetened beverages ${ }^{(9)}$. These foods are common in an obesogenic environment ${ }^{(12)}$, which may increase the likelihood for choosing unhealthy snacks, make restrained eating more difficult and result in an increased energy intake over the course of the day. A comparison between snacking patterns in 
obese adults and a reference population showed that with increasing snack occasions, energy intake from candies, chocolate, cakes, cookies and desserts increased more steeply in the obese population compared with the control population ${ }^{(13)}$.

However, high snack frequency is not in itself a reason for energy increase and weight gain. The inconsistent associations between snack frequency and body weight reported in the literature could indicate that an individual's overall nutrition pattern plays a more important role than snack frequency itself. Certain energy-dense foods with trends for increased consumption (e.g. beef, pork and pizza) were shown to be important components of meals, rather than snacks ${ }^{(14)}$. Dietary behaviour should also be considered when assessing snacking ${ }^{(6)}$, because a food that is consumed as a snack and a food that is consumed as a meal could both have a considerable influence on the quality of the diet, energy intake and weight gain.

The meal environment may be another influencing factor on dietary and eating behaviour. For example, family meals were associated with higher fruit and vegetable consumption ${ }^{(15)}$, whereas families with a higher frequency of television (TV) watching during meals reported higher proportions of energy intake from snack foods, sodas and meat ${ }^{(16)}$. In general, watching TV during dinner is considered to be a less healthy eating behaviour, and it is likely to correspond with diets high in fat and low in fruit and vegetables ${ }^{(15,16)}$. Lifestyle and socio-economic factors are likely related to different food choices as well. In the study by Holmback et al., a low daily eating frequency (referring to all eating occasions, including snacks) occurred in the context of an unhealthy lifestyle, which was defined by higher intakes of alcohol and highfat foods and low levels of leisure-time physical activity ${ }^{(7)}$. Gender differences in behaviours relating to food choices have also been observed. For example, on the whole men eat less fresh fruit and vegetables and consume more meat than do women ${ }^{(17,18)}$.

The current literature does not contain any universally accepted definition of snacking, but two main approaches have been used to define the term 'snack' ${ }^{,(6)}$. The first approach focuses on the food consumed; foods are identified as snacks by their nutrient content or because they are commonly associated with snacking ${ }^{(6,19)}$. The second approach focuses on the time of food consumption $^{(6)}$. Everything consumed between the main meals is defined as a snack. In our study, we asked for the usual frequency of food consumption between the three main meals (breakfast, lunch, dinner) and calculated 'snack frequency' per week.

The aim of the present study was to examine the associations between snack frequency, sociodemographic characteristics, BMI, dietary and eating behaviours. In order to identify whether different subgroups of high-frequency snack consumers exist, we investigated underlying food patterns and lifestyle factors. It was hypothesised that 'high snack consumers' could be separated into two groups: a group with mainly unhealthy food choices and snack consumption preferences for sweets and savouries, and a group with more healthy food choices and snack consumption preferences for items such as fruits.

\section{Methods}

\section{Procedure and sample}

The present study examined data from the Swiss Food Panel, a study into the eating behaviour of the Swiss population. In 2010, a mail survey was sent out to 20912 randomly selected household addresses from the telephone book in the German-speaking and Frenchspeaking part of Switzerland. After 5 weeks, we sent one reminder, with another copy of the questionnaire, to persons who had not yet responded. We received 6290 filled-in questionnaires (a response rate of $30 \cdot 1 \%$ ). Respondents missing either values on the Identification Code or both key variables of age and gender ( $n$ 101) were deleted from the sample. Data from 6189 (29.6\%) respondents consisting of $47 \cdot 6 \%$ males remained available for the analysis. The respondents' mean age was $54 \cdot 4$ years (SD $15 \cdot 3$; range $20-99$ years). Compared with the general Swiss population ${ }^{(20)}$, fewer males participated in the study (census $=49 \cdot 2 \%$ ), more respondents had a higher secondary or college/university degree and the percentage of young adults (20-39 years old) was lower $(18 \cdot 1 \%$ v. $26 \cdot 7 \%)$.

\section{Swiss Food Panel Questionnaire}

One part of the Swiss Food Panel Questionnaire was an FFQ, which was specially designed for the Swiss Food Panel. The FFQ was used to estimate habitual consumption frequency of various food products and snack frequency per week.

In a separate study, FFQ scales were examined on 2-week test-retest reliability. Data were analysed for 247 people who had responded to both questionnaires; the test-retest correlation between snack frequency scales was $r=0 \cdot 8$, while the scales varied between $r=0 \cdot 7$ and $r=0.9$ for food groups.

For investigating 'snack frequency per week', respondents were asked how often they usually eat a snack in the morning, an afternoon snack, an evening snack and additional snacks (e.g. a nibbling pattern, eating smaller sweets and savoury snack foods). Respondents answered on a five-point answering scale. For calculating the average weekly snack frequency during the previous year, the answering scale was recoded (daily $=360$ d/year, 4-6 times/week $=260,1-3$ times $/$ week $=104$, $1-3$ times $/$ month $=26$, less or never $=0$ ). The items were summed and divided by 52 . The calculated scores ranged from 0 to a maximum of $28 \cdot 1$. 
Table 1 Food groups and their underlying items from the FFQ, used to characterize dietary behaviour of respondents

\begin{tabular}{|c|c|c|}
\hline Food group & Selected items from the FFQ & Cronbach's $\alpha$ \\
\hline Sweets and savouriest & $\begin{array}{l}\text { Cookies } \\
\text { Chocolate } \\
\text { Sweet pastries } \\
\text { Salty snacks }\end{array}$ & $0 \cdot 71$ \\
\hline Sugar-sweetened beveragest & Beverages sweetened with sugar (e.g. Cola, Fanta) & - \\
\hline Meatt & $\begin{array}{l}\text { Beef or veal } \\
\text { Pork } \\
\text { Poultry (e.g. turkey, chicken) } \\
\text { Meat products (e.g. cold cuts, pepperoni, ham, sausages) }\end{array}$ & $0 \cdot 69$ \\
\hline Convenience food $\ddagger$ & $\begin{array}{l}\text { Pre-packed sandwiches } \\
\text { Pizza (chilled/frozen) } \\
\text { Pizza (takeaway/home delivery) } \\
\text { A meal in a can } \\
\text { Ready meals (frozen/chilled) } \\
\text { Instant noodles or pasta in a can } \\
\text { Instant noodles or pasta with powder sauce in a bag } \\
\text { Soup ready-to-heat }\end{array}$ & $0 \cdot 71$ \\
\hline Fruit§, & Fruit & - \\
\hline Vegetables§,\| & $\begin{array}{l}\text { Vegetables (cooked/steamed) } \\
\text { Salad (lettuce, tomatoes) or raw vegetables }\end{array}$ & - \\
\hline
\end{tabular}

Variables were measured using the following response categories in the FFQ: tsix response category ('several times per day', 'once a day', 'several times per week', 'several times per month', 'several times per year', 'less or never'); ffive response category ('daily', 'several times per week', 'several times per month', 'several times per year', 'less or never'); §five response category ('daily', '4-6 times/week', '1-3 times/week', '1-3 times/month', 'less or never').

IIThese items were measured with portion number and frequency of consumption.

\section{Dietary behaviour assessment}

Table 1 shows food items used in the FFQ, which were grouped into the categories 'convenience food', 'sweets and savouries', 'sugar-sweetened beverages' and 'meat'. These food groups were chosen to represent food choices, either because they had been established by dietary guidelines or because their high frequency of consumption had been shown to have unfavourable health effects ${ }^{(21-23)}$.

The questionnaire did not collect information on portion size or number of portions, except for fruit and vegetable consumption.

Items relating to sweets and savouries, sugar-sweetened beverages and meat consumption frequency were assessed on a six-point answering scale. For statistical calculation, 'several times per day' was assumed to be 2 times/d (coded as 14 times/week), 'daily' was assumed to be 1 time/d (coded as 7 times/week), 'several times per week' was assumed to be 3 times/week (coded as 3 times/week), 'several times per month' was assumed to be 3 times/month (coded as 0.75 times/week), 'several times per year' and 'less or never' were considered as negligible (coded as 0). Items falling into each food group were summed to reflect consumption frequency of these foods per week.

Convenience food consumption was assessed on a fivepoint answering scale: 'daily' (coded as 7 times/week), 'several times per week' (coded as 3 times/week), 'several times per month' (coded as 0.75 times/week), 'several times per year' (coded as 0) and 'less or never' (coded as 0 ). To reflect weekly consumption frequency the items were summed.

Fruit and vegetable consumption was assessed on a fivepoint answering scale: 'daily' (coded as 7 times/week), ‘4-6 times/week' (coded as 5 times/week), '1-3 times/week' (coded as 2 times/week), '1-3 times/month' (coded as 0.5 times/week) and 'less or never' (coded as 0 ). Additionally respondents were asked how many portions of vegetables (one portion $=\mathrm{a}$ handful, or $50 \mathrm{~g}$ ) and fruit (one piece or one handful) they usually eat. The items relating to portion number and consumption frequency were combined to reflect 'servings' of vegetables and 'pieces' of fruit consumed per week.

Additionally, the internal reliability of items from the convenience foods scale, meat scale and the sweets and savouries scale were explored using Cronbach's $\alpha$ (Table 1).

\section{Eating behaviour assessment}

'Meal frequency' was assessed by asking respondents how often they usually eat breakfast, lunch and dinner. The answering scale was as follows: 'daily', '4-6 times/ week', '1-3 times/week', '1-3 times/month' and 'less or never'. Two-week test-retest reliability was $r=0 \cdot 88$ for breakfast, $r=0.73$ for lunch and $r=0.68$ for dinner. Two additional items assessed the frequency of 'family meals' and 'watching television during the main meal' on a five-point answering scale ('daily', '4-6 times/week', '1-3 times/week', '1-3 times/month', 'less or never').

Because the items meal frequency, family meals and watching TV during the main meal were highly skewed, they were categorised into binary variables indicating daily breakfast (yes/no), daily lunch (yes/no), daily dinner (yes/no), having family meals 4-7 times/week (yes/no) and watching TV during the main meal 4-7 times/week (yes/no).

\section{Sociodemographic and lifestyle variables}

Age, gender, having children ( $\leq 16$ years old), weight and height were all assessed in the Swiss Food Panel 
Questionnaire. Educational level was categorised in three groups: (i) low (primary and secondary school), (ii) medium (vocational school) and (iii) high (college and university). BMI $\left(\mathrm{kg} / \mathrm{m}^{2}\right)$ was calculated from the self-reported body weight $(\mathrm{kg})$ divided by square of the self-reported height $\left(\mathrm{m}^{2}\right)$ of respondents (range $\left.15 \cdot 3-62 \cdot 1 \mathrm{~kg} / \mathrm{m}^{2}\right)$. Respondents with a BMI $\geq 25 \mathrm{~kg} / \mathrm{m}^{2}$ were classified as being overweight.

'Wine and beer consumption frequency per week' was also assessed. Respondents stated on a six-point answering scale how often they usually drink wine and beer: 'several times per day', 'once a day', 'several times per week', 'several times per month', 'several times per year' or 'less or never'.

'Average daily physical activity' was calculated from two items in the questionnaire. A short introduction encouraged the respondents to take into account only physical activity above a minimum of $10 \mathrm{~min}$. The questions then asked were: 'During the last seven days, on how many days did you do physical activities like heavy lifting, digging, sports, cycling or walking?' and 'How much time did you usually spend on one of those days doing physical activities?'. The second item had to be answered by filling in the minutes per day. Respondents with missing values in one of the two items and with values less than $10 \mathrm{~min}$ or more than 960 min were coded as missing (13.9\% missing values). Additionally, physical activity was grouped into two categories: physical activity $\geq 30 \mathrm{~min} / \mathrm{d}$ ( $n$ 3588) and less physical activity ( $n$ 1738).

'Health consciousness' $(\alpha=0 \cdot 79)$ related to eating was assessed with following statements using a six-point answering scale ranging from $1=$ 'do not agree at all' to $6=$ 'totally agree': 'I think it is important to eat healthily', 'My health is dependent on how and what I eat', 'If one eats healthily, one gets ill less frequently' and 'I am prepared to leave a lot, to eat as healthily as possible ${ }^{,(24)}$.

\section{Data analysis}

Data were analysed to examine which eating behaviours, dietary behaviours, sociodemographic and lifestyle factors were of importance for high snack frequency. All analyses were performed using the statistical software package IBM SPSS Statistics $19 \cdot 0$.

First, one-way ANOVA and $\chi^{2}$ tests were used to evaluate gender differences in eating behaviours, dietary behaviours, and lifestyle and sociodemographic variables. Additionally, the study population was categorised into tertiles based on weekly snack frequency (high, moderate, low). The highest tertile included all respondents who indicated having a snack frequency between 7.5 and $20 \cdot 1$ times/week, the moderate tertile included all respondents who indicated having a snack frequency between 2.5 and $7 \cdot 0$ times/week, and the lowest tertile included all respondents who indicated having a snack frequency between 0 and $2 \cdot 0$ times/week. One-way ANOVA and $\chi^{2}$ tests were used for examining differences in mean scores for all variables between tertiles. ANOVA and $\chi^{2}$ tests were done for males and females separately. Significant $F$ tests were followed up by the examination of contrasts using the Tukey Honestly Significant Difference test.

Second, linear regression analysis was used to identify associations between snack frequency as the dependent variable and the other characteristics. No cases of multicollinearity were detected by bivariate correlations.

Third, cluster analysis was used to identify relatively homogeneous profiles of dietary behaviours, using only the respondents from the highest snack-frequency tertile ( $n$ 1890). Clustering variables were the six dietary behaviours: consumption frequency of vegetables, fruit, convenience foods, sweets and savouries, sugar-sweetened beverages and meat. Hierarchical, agglomerative cluster analysis was performed with the squared Euclidean distance as the distance measure in the clustering procedure. Therefore, the procedure was accomplished using standardized scores (Z-scores), employing Ward's method. Cluster solutions of two to eight segments were generated initially. The final cluster solution was chosen by examining the agglomeration schedule. The three-cluster solution was found to be adequate and meaningful regarding the different patterns found, and therefore it is reported in the results section (Table 5). Comparisons of the three clusters based on eating behaviour, sociodemographic and lifestyle factors are displayed separately for male and female respondents (Table 6).

\section{Results}

Table 2 shows snack frequency, eating behaviours, dietary behaviours, and sociodemographic and lifestyle variables by gender. Mean snack frequency per week was higher for females ( 6.6 times/week) than for males (5.2 times/week). Females indicated having higher vegetable and fruit consumption, while males reported higher mean intakes of meat, sugar-sweetened beverages and convenience food. Males were also less likely to have a daily breakfast and lunch, were less health-conscious, had higher BMI, were more physically active, had a higher mean consumption of wine and beer, were older, had a higher educational level and were less likely to have children. No significant gender difference was found for having dinner on a daily basis, or for consumption of sweets and savouries.

Table 3 presents the investigated variables by tertiles of snack frequency per week, showing males and females separately. The dietary behaviours in the highest snackfrequency tertile were different from those in the lowest group with respect to higher frequency consumption of all food groups, with the exception of vegetable consumption in females. Male respondents with a low snack frequency were more likely to be older, eat main meals 
Table 2 Characteristics of the study population according to gender: Swiss adults, 2010 (Swiss Food Panel)

\begin{tabular}{|c|c|c|c|c|c|c|}
\hline & \multicolumn{2}{|c|}{ Males ( $n$ 2938)† } & \multicolumn{2}{|c|}{ Females $(n$ 3234)† } & \multirow[b]{2}{*}{$F$ or $\chi^{2}$} & \multirow[b]{2}{*}{$\mathrm{df}_{1}, \mathrm{df}_{2}$ or $\mathrm{d}$} \\
\hline & Mean or \% & SD & Mean or \% & SD & & \\
\hline \multicolumn{7}{|l|}{ Eating behaviour } \\
\hline Snack frequency per week & $5 \cdot 2$ & $5 \cdot 4$ & $6 \cdot 6$ & $5 \cdot 8$ & $90 \cdot 7^{\star \star \star}$ & $1,6103 \ddagger$ \\
\hline Daily breakfast (\%) & $66 \cdot 6$ & - & $71 \cdot 9$ & - & $19 \cdot 8^{\star \star \star}$ & 1 \\
\hline Daily lunch (\%) & $72 \cdot 0$ & - & $76 \cdot 8$ & - & $18 \cdot 8^{\star \star \star}$ & 1 \\
\hline Daily dinner (\%) & $82 \cdot 3$ & - & $83 \cdot 0$ & - & $0.5^{\mathrm{NS}}$ & 1 \\
\hline Having family meals $4-7$ times/week (\%) & $71 \cdot 3$ & - & $64 \cdot 7$ & - & $29 \cdot 6^{\star \star \star}$ & 1 \\
\hline Watching TV during the main meal 4-7 times/week (\%) & $11 \cdot 5$ & - & $14 \cdot 0$ & - & $8 \cdot 1^{\star \star}$ & 1 \\
\hline \multicolumn{7}{|l|}{ Dietary behaviour (consumption frequency per week) } \\
\hline Sweets and savouries & $4 \cdot 7$ & $4 \cdot 9$ & $4 \cdot 6$ & $4 \cdot 8$ & $0 \cdot 7^{\mathrm{NS}}$ & $1,6049 \ddagger$ \\
\hline Sugar-sweetened beverages & 0.8 & $2 \cdot 0$ & 0.3 & $1 \cdot 3$ & $102 \cdot 1^{\star \star \star}$ & $1,6083 \ddagger$ \\
\hline Meat & $5 \cdot 7$ & $4 \cdot 2$ & $4 \cdot 0$ & $3 \cdot 3$ & $280 \cdot 2^{\star \star \star}$ & $1,6065 \ddagger$ \\
\hline Convenience food & $1 \cdot 2$ & $2 \cdot 6$ & 0.7 & $1 \cdot 5$ & $72 \cdot 1^{\star \star \star}$ & $1,5984 \ddagger$ \\
\hline Vegetables (servings/week) & $17 \cdot 9$ & $10 \cdot 9$ & $21 \cdot 4$ & $11 \cdot 5$ & $146 \cdot 9^{\star \star \star}$ & $1,6066 \ddagger$ \\
\hline Fruit (pieces/week) & $8 \cdot 8$ & $7 \cdot 9$ & $11 \cdot 2$ & $8 \cdot 0$ & $143 \cdot 9^{\star \star \star}$ & $1,6083 \ddagger$ \\
\hline \multicolumn{7}{|l|}{ Sociodemographic and lifestyle characteristics } \\
\hline Age (years) & $56 \cdot 9$ & $15 \cdot 1$ & $52 \cdot 1$ & $15 \cdot 1$ & $155 \cdot 6^{\star \star \star}$ & $1,6089 \ddagger$ \\
\hline Health consciousness & $4 \cdot 4$ & $1 \cdot 0$ & $4 \cdot 7$ & 0.9 & $144 \cdot 3^{\star \star \star}$ & $1,6088 \ddagger$ \\
\hline Wine and beer consumption frequency per week & $3 \cdot 4$ & $3 \cdot 7$ & $1 \cdot 6$ & $2 \cdot 4$ & $463 \cdot 3^{\star \star \star}$ & $1,6129 \ddagger$ \\
\hline BMI $\left(\mathrm{kg} / \mathrm{m}^{2}\right)$ & $25 \cdot 8$ & $3 \cdot 7$ & 23.5 & $4 \cdot 3$ & $491 \cdot 5^{\star \star \star}$ & $1,6097 \ddagger$ \\
\hline Overweight (\%) & $54 \cdot 0$ & - & $28 \cdot 0$ & - & $429 \cdot 4^{\star \star \star}$ & 1 \\
\hline Physical activity $\geq 30 \mathrm{~min} / \mathrm{d}(\%)$ & $66 \cdot 6$ & - & $60 \cdot 2$ & - & $25 \cdot 3^{\star \star \star}$ & 1 \\
\hline Having children $\leq 16$ years old $(\%)$ & $20 \cdot 3$ & - & $29 \cdot 1$ & - & $61 \cdot 7^{\star \star \star}$ & 1 \\
\hline \multicolumn{7}{|l|}{ Education (\%) } \\
\hline Low & $8 \cdot 9$ & - & $12 \cdot 6$ & - & $50 \cdot 2^{\star \star \star}$ & 2 \\
\hline Middle & $34 \cdot 8$ & - & $39 \cdot 6$ & - & & \\
\hline High & $56 \cdot 3$ & - & $47 \cdot 8$ & - & & \\
\hline
\end{tabular}

TV, television.

${ }^{\star} P<0.05,{ }^{* \star} P<0.01,{ }^{* \star \star} P<0.001$

t $n$ could vary due to missing values.

$\ddagger$ Values are indicated as $\mathrm{df}_{1}, \mathrm{df}_{2}$.

on a more regular basis and to indicate having family meals more often than male respondents with highfrequency snack consumption. Female respondents with high-frequency snack consumption were more likely to skip breakfast and to report lower health consciousness compared with female respondents in the lowest snackfrequency group.

Table 4 illustrates the results of the regression analysis with snack frequency as the dependent variable ( $n$ 4871). Seven variables showed a significant effect $(P \leq 0 \cdot 01)$, and the model accounted for $23 \%$ of the variance in snack frequency per week. Significant positive associations were found for sweets and savouries $(\beta=0 \cdot 34)$, fruit $(\beta=0 \cdot 13)$ and watching TV during the main meal $(\beta=0 \cdot 04)$. Inverse associations were found for having family meals $4-7$ times/week $(\beta=-0 \cdot 04)$, age $(\beta=-0 \cdot 23)$, high educational level $(\beta=-0 \cdot 09)$ and wine and beer consumption frequency $(\beta=-0 \cdot 08)$.

\section{Chusters of bigh-frequency snack consumers}

The cluster analysis resulted in a three-cluster solution for high snack consumers ( $n$ 1890) with Cluster 1 representing a healthy dietary pattern, Cluster 2 representing a moderate dietary pattern and Cluster 3 characterized by an unhealthy dietary pattern (Tables 5 and 6).

The healthy Cluster 1 ( $n$ 851) consisted mainly of older females, and was characterized by the highest consumption of vegetables and fruit and the lowest consumption frequency of more unhealthy food groups such as sweets and savouries, and meat. Respondents in this cluster reported the highest levels of health consciousness and reported more regular breakfast consumption. This cluster mostly included higher educated males.

The unhealthy Cluster 3 ( $n$ 85) was the smallest cluster and consisted mainly of males. It was characterized by the highest consumption frequency of the more unhealthy foods and low fruit and vegetable consumption. A higher percentage of respondents skipped breakfast on a daily basis and watched TV during the main meal, compared with the other two clusters. In addition, wine and beer consumption frequency in males was the highest in this cluster.

Cluster 2 was the largest group ( $n$ 954) and respondents in this cluster had dietary behaviours ranging between the healthy and unhealthy clusters. Females in this cluster indicated having moderate consumption frequencies of the more unhealthy food groups, such as sugar-sweetened beverages and meat, but also had infrequent intakes of fruit and vegetables. Males in this cluster reported moderate consumption frequencies of sugar-sweetened beverages and convenience food, but also infrequent intakes of fruit and vegetables. 
Table 3 Characteristics of the study population according to tertile of snack frequency per week ( $n$ 6105): Swiss adults, 2010 (Swiss Food Panel)

\begin{tabular}{|c|c|c|c|c|c|c|c|c|c|c|c|c|c|c|c|c|}
\hline \multirow[b]{4}{*}{ Characteristic } & \multicolumn{12}{|c|}{ Tertiles of snack frequency per week } & & & & \\
\hline & \multicolumn{4}{|c|}{ Highestt } & \multicolumn{4}{|c|}{ Moderate } & \multicolumn{4}{|c|}{ Lowest§ } & & & & \\
\hline & \multicolumn{2}{|c|}{$\begin{array}{l}\text { Males } \\
(n \text { 809)\| }\end{array}$} & \multicolumn{2}{|c|}{$\begin{array}{l}\text { Females } \\
(n \text { 1200) } \|\end{array}$} & \multicolumn{2}{|c|}{$\begin{array}{l}\text { Males } \\
(n 878) \|\end{array}$} & \multicolumn{2}{|c|}{$\begin{array}{l}\text { Females } \\
(n 985) \|\end{array}$} & \multicolumn{2}{|c|}{$\begin{array}{c}\text { Males } \\
(n \text { 1227)\| }\end{array}$} & \multicolumn{2}{|c|}{$\begin{array}{l}\text { Females } \\
(n \text { 1006) } \|\end{array}$} & \multicolumn{2}{|c|}{ Males } & \multicolumn{2}{|c|}{ Females } \\
\hline & $\begin{array}{l}\text { Mean } \\
\text { or } \%\end{array}$ & SD & $\begin{array}{l}\text { Mean } \\
\text { or } \%\end{array}$ & SD & $\begin{array}{l}\text { Mean } \\
\text { or \% }\end{array}$ & SD & $\begin{array}{l}\text { Mean } \\
\text { or \% }\end{array}$ & SD & $\begin{array}{l}\text { Mean } \\
\text { or \% }\end{array}$ & SD & $\begin{array}{l}\text { Mean } \\
\text { or } \%\end{array}$ & SD & $F$ or $\chi^{2}$ & $\mathrm{df}_{1}, \mathrm{df}_{2}$ or & $F$ or $\chi^{2}$ & $\mathrm{df}_{1}, \mathrm{df}_{2}$ or \\
\hline \multicolumn{17}{|l|}{ Eating behaviours } \\
\hline Snack frequency per week & $12 \cdot 3^{\mathrm{a}}$ & $4 \cdot 4$ & $12 \cdot 7^{\mathrm{x}}$ & $4 \cdot 2$ & $4 \cdot 8^{b}$ & $1 \cdot 6$ & $5 \cdot 0^{y}$ & $1 \cdot 6$ & $0 \cdot 7^{\mathrm{c}}$ & $0 \cdot 8$ & $0 \cdot 8^{z}$ & $1 \cdot 6$ & $5145 \cdot 2^{\star \star \star}$ & 2,2911 ब & $5283 \cdot 9^{\star \star \star}$ & $2,3188^{\top}$ \\
\hline Daily breakfast (\%) & $58 \cdot 5$ & - & $66 \cdot 8$ & - & 62.5 & - & $71 \cdot 7$ & - & $74 \cdot 8$ & - & $77 \cdot 7$ & - & $67 \cdot 6^{\star \star *}$ & 2 & $32 \cdot 2^{\star \star \star}$ & 2 \\
\hline Daily lunch (\%) & $69 \cdot 7$ & - & $77 \cdot 9$ & - & $68 \cdot 0$ & - & $76 \cdot 0$ & - & $76 \cdot 2$ & - & $76 \cdot 0$ & _- & $19 \cdot 6^{\star \star \star}$ & 2 & $1 \cdot 6^{\mathrm{NS}}$ & 2 \\
\hline Daily dinner (\%) & $80 \cdot 8$ & - & $84 \cdot 6$ & - & $80 \cdot 6$ & - & $80 \cdot 9$ & - & $84 \cdot 4$ & - & $82 \cdot 9$ & - & $6 \cdot 7^{\star}$ & 2 & $5 \cdot 4^{\mathrm{NS}}$ & 2 \\
\hline Family meals $4-7$ times/week (\%) & $63 \cdot 0$ & - & $66 \cdot 6$ & - & $68 \cdot 6$ & - & $65 \cdot 9$ & - & $78 \cdot 5$ & - & $61 \cdot 1$ & - & $60 \cdot 7^{\star \star \star}$ & 2 & $7 \cdot 8^{\star}$ & 2 \\
\hline $\begin{array}{l}\text { Watching TV during the main meal } \\
4-7 \text { times/week }(\%)\end{array}$ & $14 \cdot 6$ & - & $15 \cdot 4$ & - & $11 \cdot 8$ & - & $11 \cdot 6$ & - & $9 \cdot 3$ & - & $14 \cdot 6$ & - & $13 \cdot 0^{\star \star}$ & 2 & $6 \cdot 8^{*}$ & 2 \\
\hline \multicolumn{17}{|l|}{$\begin{array}{l}\text { Dietary behaviours (consumption frequency } \\
\text { per week) }\end{array}$} \\
\hline Sweets and savouries & $6 \cdot 9^{a}$ & $6 \cdot 4$ & $6 \cdot 4^{x}$ & $5 \cdot 8$ & $4 \cdot 8^{b}$ & $4 \cdot 4$ & $4 \cdot 1^{y}$ & $3 \cdot 7$ & $3 \cdot 1^{c}$ & $3 \cdot 3$ & $2 \cdot 9^{z}$ & $3 \cdot 4$ & $150 \cdot 8^{\star \star \star}$ & 2,2857 & $172 \cdot 3^{\star \star \star}$ & 2,3125 \\
\hline Sugar-sweetened beverages & $1 \cdot 1^{\mathrm{a}}$ & $2 \cdot 3$ & $0 \cdot 5^{x}$ & $1 \cdot 6$ & $0 \cdot 8^{\mathrm{b}}$ & $2 \cdot 0$ & $0 \cdot 3^{y}$ & $1 \cdot 3$ & $0 \cdot 5^{\mathrm{c}}$ & $1 \cdot 6$ & $0 \cdot 2^{y}$ & $1 \cdot 3$ & $23 \cdot 1^{\star * *}$ & 2,2873 & $12 \cdot 2^{\star \star \star}$ & 2,3147 \\
\hline Meat & $6 \cdot 4^{\mathrm{a}}$ & $5 \cdot 2$ & $4 \cdot 3^{x}$ & $3 \cdot 4$ & $5 \cdot 6^{\mathrm{b}}$ & $3 \cdot 7$ & $4 \cdot 0^{x, y}$ & $3 \cdot 1$ & $5 \cdot 2^{\mathrm{b}}$ & $3 \cdot 7$ & $3 \cdot 8^{y}$ & $3 \cdot 2$ & $19 \cdot 0^{\star \star *}$ & 2,2872 & $9 \cdot 2^{\star \star \star}$ & 2,3124 \\
\hline Convenience food & $1 \cdot 7^{\mathrm{a}}$ & $3 \cdot 6$ & $0 \cdot 8^{x}$ & $1 \cdot 6$ & $1 \cdot 1^{\mathrm{b}}$ & $1 \cdot 9$ & $0 \cdot 8^{x}$ & 1.5 & $0 \cdot 8^{\mathrm{C}}$ & $1 \cdot 6$ & $0.5^{\mathrm{b}}$ & $1 \cdot 2$ & $36 \cdot 5^{\star \star *}$ & 2,2859 & $14 \cdot 1^{\star \star \star}$ & 2,3105 \\
\hline Vegetables & $18 \cdot 5^{\mathrm{a}}$ & $11 \cdot 1$ & $21 \cdot 4$ & $11 \cdot 2$ & $18 \cdot 0^{\mathrm{a}, \mathrm{b}}$ & $10 \cdot 9$ & $21 \cdot 3$ & $10 \cdot 8$ & $17 \cdot 3^{\mathrm{b}}$ & $10 \cdot 7$ & $21 \cdot 6$ & $12 \cdot 3$ & $3 \cdot 4^{*}$ & 2,2884 & $0 \cdot 6^{\mathrm{NS}}$ & 2,3160 \\
\hline Fruit & $9 \cdot 3^{\mathrm{a}}$ & $7 \cdot 7$ & $11 \cdot 9^{x}$ & $8 \cdot \overline{0}$ & $8 \cdot 5^{\mathrm{a}, \mathrm{b}}$ & $7 \cdot 8$ & $10 \cdot 6^{y}$ & $7 \cdot 8$ & $8 \cdot 2^{b, c}$ & $7 \cdot 7$ & $10 \cdot 6^{y}$ & $8 \cdot 0$ & $4 \cdot 7^{\star \star}$ & 2,2897 & $7 \cdot 0^{\star *}$ & 2,3163 \\
\hline \multicolumn{17}{|l|}{$\begin{array}{l}\text { Sociodemographic and lifestyle } \\
\text { characteristics }\end{array}$} \\
\hline Age (years) & $49 \cdot 6^{\mathrm{a}}$ & $13 \cdot 8$ & $46 \cdot 6^{\mathrm{x}}$ & $13 \cdot 4$ & $54 \cdot 8^{\mathrm{b}}$ & $14 \cdot 4$ & $51 \cdot 0^{y}$ & $14 \cdot 0$ & $61 \cdot 9^{c}$ & $13 \cdot 9$ & $56 \cdot 7^{z}$ & $14 \cdot 6$ & $181 \cdot 5^{\star \star \star}$ & 2,2870 ฯ & $145 \cdot 8^{\star \star \star}$ & 2, 3149 \\
\hline Health consciousness & $4 \cdot 3^{\mathrm{a}}$ & $1 \cdot 0$ & $4 \cdot 6^{\mathrm{x}}$ & 0.9 & $4 \cdot 4^{\mathrm{a}}$ & $1 \cdot 0$ & $4 \cdot 7^{\mathrm{x}}$ & 0.9 & $4 \cdot 5^{\mathrm{b}}$ & $1 \cdot 0$ & $4 \cdot 9^{y}$ & 0.9 & $9 \cdot 6^{\star \star \star}$ & 2,2891 - & $14 \cdot 3^{\star \star \star}$ & 2,3132 \\
\hline $\begin{array}{l}\text { Wine and beer consumption frequency } \\
\text { per week }\end{array}$ & $2 \cdot 9^{\mathrm{a}}$ & $3 \cdot 6$ & $1 \cdot 3^{x}$ & $2 \cdot 1$ & $3 \cdot 3^{b}$ & 3.5 & $1 \cdot 6^{y}$ & $2 \cdot 2$ & $3 \cdot 7^{\mathrm{b}}$ & 3.9 & $2 \cdot 0^{z}$ & $2 \cdot 7$ & $9 \cdot 3^{\star \star}$ & $2,2887 \uparrow$ & $27 \cdot 9^{\star \star \star}$ & 2,3164 \\
\hline BMI $\left(\mathrm{kg} / \mathrm{m}^{2}\right)$ & $25 \cdot 4^{a}$ & 3.5 & $23 \cdot 2^{x}$ & $4 \cdot 3$ & $25 \cdot 9^{b}$ & $4 \cdot 0$ & $23 \cdot 6^{y}$ & $4 \cdot 3$ & $26 \cdot 0^{b}$ & 3.5 & $23 \cdot 6^{y}$ & $4 \cdot 2$ & $6 \cdot 9^{\mathrm{NS}}$ & $2,2887-$ & $4 \cdot 6^{\star \star}$ & 2,3149 \\
\hline Overweight (\%) & $47 \cdot 8$ & - & $23 \cdot 9$ & - & $54 \cdot 0$ & - & $30 \cdot 5$ & - & $58 \cdot 1$ & - & $29 \cdot 5$ & - & $20 \cdot 9^{\star \star \star}$ & 2 & $13 \cdot 8^{\star \star}$ & 2 \\
\hline Physical activity $\geq 30 \mathrm{~min} / \mathrm{d}(\%)$ & $66 \cdot 4$ & - & $59 \cdot 0$ & - & $63 \cdot 4$ & - & $59 \cdot 7$ & - & $69 \cdot 5$ & - & $62 \cdot 5$ & - & $8 \cdot 0^{*}$ & 2 & $0 \cdot 3^{\mathrm{NS}}$ & 2 \\
\hline Having children $\leq 16$ years old (\%) & $27 \cdot 2$ & - & $36 \cdot 7$ & - & $21 \cdot 2$ & - & $30 \cdot 6$ & - & $15 \cdot 2$ & - & $18 \cdot 6$ & - & $42 \cdot 3^{\star \star \star}$ & 2 & $83 \cdot 6^{\star \star \star}$ & 2 \\
\hline \multicolumn{17}{|l|}{ Education (\%) } \\
\hline Low & $9 \cdot 2$ & - & $11 \cdot 3$ & - & $7 \cdot 5$ & - & $11 \cdot 3$ & - & $9 \cdot 4$ & - & $14 \cdot 7$ & - & $10 \cdot 8^{*}$ & 4 & $2 \cdot 7^{\mathrm{NS}}$ & 2 \\
\hline Middle & $38 \cdot 6$ & - & $40 \cdot 1$ & - & $34 \cdot 8$ & - & $40 \cdot 6$ & - & $32 \cdot 5$ & - & $38 \cdot 4$ & - & & & & \\
\hline High & $52 \cdot 2$ & - & $48 \cdot 6$ & - & $57 \cdot 7$ & - & $48 \cdot 0$ & - & $58 \cdot 1$ & - & $46 \cdot 9$ & - & & & & \\
\hline
\end{tabular}

\section{TV, television}

a,b,c,x,y,zOne-way ANOVA, and $\chi^{2}$ tests were used for examining differences between tertiles. Analysis was done for males and females separately. Mean values within rows with unlike superscript letters were significantly different (post hoc test: Tukey's Honestly Significant Difference test, $P<0 \cdot 05$ ): ${ }^{a, b, c}$ for significant differences between tertiles for males; ${ }^{x, y, z}$ for significant differences between tertiles for females. ${ }^{* \star} P<0.01,{ }^{* \star *} P<0.001$

thighest tertile includes all respondents who indicated having a snack frequency between 7.5 and $20 \cdot 1$ times/week.

‡Moderate tertile includes all respondents who indicated having a snack frequency between 2.5 and 7.0 times/week.

$\S$ Lowest tertile includes all respondents who indicated having a snack frequency between 0 and $2 \cdot 0$ times/week.

$\| n$ could vary due to missing values.

- Values are indicated as $\mathrm{df}_{1}, \mathrm{df}_{2}$. 
Table 4 Results from the multiple regression analysis with snack frequency per week as the dependent variable ( $n$ 4871): Swiss adults, 2010 (Swiss Food Panel)

\begin{tabular}{|c|c|c|c|c|}
\hline & $\beta$ & SE $\beta$ & Standard $\beta$ & $P$ value \\
\hline \multicolumn{5}{|l|}{ Eating behaviours } \\
\hline Daily breakfast (yes $=1 /$ no $=0$ ) & $-0 \cdot 38$ & $0 \cdot 17$ & -0.03 & 0.026 \\
\hline Daily lunch $($ yes $=1 /$ no $=0)$ & $0 \cdot 20$ & $0 \cdot 18$ & 0.02 & 0.368 \\
\hline Daily dinner $($ yes $=1 /$ no $=0)$ & 0.43 & $0 \cdot 20$ & 0.03 & 0.032 \\
\hline Having family meals $4-7$ times/week $($ yes $=1 /$ no $=0$ ) & $-0 \cdot 43$ & $0 \cdot 17$ & -0.04 & 0.009 \\
\hline $\begin{array}{l}\text { Watching TV during the main meal } 4-7 \text { times/week } \\
\text { (yes }=1 / \text { no }=0 \text { ) }\end{array}$ & $0 \cdot 72$ & $0 \cdot 23$ & 0.04 & 0.001 \\
\hline \multicolumn{5}{|l|}{ Dietary behaviours (consumption frequency per week) } \\
\hline Sweets and savouries & $0 \cdot 40$ & 0.02 & 0.34 & 0.000 \\
\hline Sugar-sweetened beverages & 0.06 & 0.05 & 0.02 & 0.236 \\
\hline Meat & -0.03 & 0.02 & $-0 \cdot 02$ & $0 \cdot 165$ \\
\hline Convenience food & 0.04 & 0.04 & $0 \cdot 01$ & $0 \cdot 301$ \\
\hline Vegetables & -0.05 & 0.05 & -0.01 & 0.308 \\
\hline Fruit & $0 \cdot 67$ & 0.07 & $0 \cdot 13$ & 0.000 \\
\hline \multicolumn{5}{|l|}{ Sociodemographic and lifestyle characteristics } \\
\hline Age (years) & $-0 \cdot 09$ & 0.01 & -0.23 & 0.000 \\
\hline Health consciousness & 0.08 & 0.08 & 0.01 & $0 \cdot 316$ \\
\hline Wine and beer consumption frequency per week & $-0 \cdot 14$ & 0.03 & -0.08 & 0.000 \\
\hline BMI & $-0 \cdot 02$ & 0.02 & $-0 \cdot 01$ & 0.419 \\
\hline Physical activity $\geq 30 \mathrm{~min} / \mathrm{d}($ yes $=1 / \mathrm{no}=0)$ & 0.06 & $0 \cdot 15$ & $0 \cdot 01$ & $0 \cdot 715$ \\
\hline Having children $\leq 16$ years $($ yes $=1 / \mathrm{no}=0$ ) & $0 \cdot 24$ & $0 \cdot 19$ & 0.02 & 0.205 \\
\hline Gender (females) & $0 \cdot 32$ & $0 \cdot 17$ & 0.03 & 0.052 \\
\hline \multicolumn{5}{|l|}{ Education } \\
\hline Medium $v$. low & $-0 \cdot 43$ & $0 \cdot 28$ & -0.04 & $0 \cdot 126$ \\
\hline High $v$. low & -0.98 & 0.27 & -0.09 & 0.000 \\
\hline
\end{tabular}

TV, television.

Significant coefficients are indicated in bold font. $R^{2}=0 \cdot 23$.

The variables of BMI, percentage of overweight, percentage of physically active males, daily lunch for males, having family meals $4-7$ times/week and having children $\leq 16$ years old did not differ significantly among clusters.

\section{Discussion}

We investigated snack frequency and its association with sociodemographic characteristics, dietary and eating behaviour, and lifestyle factors. We hypothesised that high-frequency snack consumers could be separated into different subgroups with different underlying food patterns and lifestyle factors.

Our results show that high-frequency snack consumers (with at least 7.5 snack occasions/week) more frequently consumed both healthy and unhealthy food groups compared with low-frequency snack consumers. Increasing snack frequency was associated with a more unhealthy dietary behaviour, such as consuming sweets and savouries. It was also associated with watching TV during the main meal, having fewer family meals and lower alcohol intake. Fruit consumption was positively associated with snack frequency, indicating higher fruit intake with increasing snack frequency. Finally, we found three subgroups of high-frequency snack consumers: a healthy, a moderate and an unhealthy dietary-pattern group.

The highest levels of health consciousness were reported by respondents in the healthy and moderate eating clusters, indicating that individuals in these groups tended to act more in accordance with their internal attitudes towards health than the less health-conscious individuals, who might be more subject to external influences ${ }^{(25)}$. Thus, less health-conscious individuals might be more affected by the obesogenic environment, which makes a healthy lifestyle, and particularly the healthy food choices associated with this lifestyle, more difficult.

Differences in health-conscious ratings could also be seen between genders; men seemed to be less healthconscious than women. Therefore, women were more likely to be mindful of their daily diet and to make healthier food choices. Former studies indicate that men give a lower priority to health than to other considerations, like taste or convenience, when making their food choices $^{(26,27)}$. It is thus not surprising that men in our study showed higher-frequency consumption of meat, sugar-sweetened beverages and alcohol. In addition, the highest frequency of convenience food consumption occurred in males in the unhealthy cluster. Convenience food consumption was also shown to be an unfavourable dietary behaviour, as it was associated with obesity ${ }^{(22)}$. As reported in other studies, our results suggest that men practise an unhealthy lifestyle more often than do women ${ }^{(28)}$.

BMI was not found to be associated with snack frequency in the regression analysis. Thus, the results of our study do not support the notion that increased snack frequency, in itself, is a cause of obesity. However, 
Table 5 Cluster centres for the six dietary behaviours included in the cluster analysis; presented for males and females separately: Swiss adults, 2010 (Swiss Food Panel)

\begin{tabular}{|c|c|c|c|c|c|c|c|c|c|c|c|c|c|c|}
\hline \multirow[b]{3}{*}{ Clustering factors } & \multicolumn{4}{|c|}{ Cluster 1: ‘Healthy’ } & \multicolumn{4}{|c|}{ Cluster 2: 'Moderate' } & \multicolumn{4}{|c|}{ Cluster 3: 'Unhealthy' } & \multicolumn{2}{|c|}{ F statistic } \\
\hline & \multicolumn{2}{|c|}{ Males ( $n$ 254) } & \multicolumn{2}{|c|}{ Females ( $n$ 597) } & \multicolumn{2}{|c|}{ Males ( $n$ 456) } & \multicolumn{2}{|c|}{ Females ( $n$ 498) } & \multicolumn{2}{|c|}{ Males ( $n$ 52) } & \multicolumn{2}{|c|}{ Females ( $n$ 33) } & \multirow{2}{*}{$\frac{\text { Males }}{F(2,759)}$} & \multirow{2}{*}{$\frac{\text { Females }}{F(2,1125}$} \\
\hline & Mean & SD & Mean & SD & Mean & SD & Mean & SD & Mean & SD & Mean & SD & & \\
\hline Sweets and savouries & $7 \cdot 2^{\mathrm{a}}$ & $7 \cdot 5$ & $6 \cdot 8^{x}$ & $6 \cdot 5$ & $6 \cdot 2^{\mathrm{a}}$ & $4 \cdot 7$ & $5 \cdot 9^{y}$ & $4 \cdot 7$ & $10 \cdot 3^{\mathrm{b}}$ & $10 \cdot 4$ & $8 \cdot 1^{x, y}$ & $6 \cdot 5$ & $16 \cdot 3^{\star \star \star}$ & $11 \cdot 2^{* * *}$ \\
\hline Sugar-sweetened beverages & $0 \cdot 4^{\mathrm{a}}$ & $1 \cdot 3$ & $0 \cdot 1^{x}$ & 0.4 & $0 \cdot 8^{b}$ & $1 \cdot 2$ & $0 \cdot 4^{y}$ & $8 \cdot 7$ & $7 \cdot 5^{\mathrm{c}}$ & $3 \cdot 8$ & $7 \cdot 9^{z}$ & $3 \cdot 4$ & $470 \cdot 1^{\star \star \star}$ & $1243 \cdot 4^{\star \star \star}$ \\
\hline Meat & $5 \cdot 5^{\mathrm{a}}$ & $6 \cdot 2$ & $3 \cdot 6^{x}$ & $3 \cdot 1$ & $6 \cdot 2^{\mathrm{a}}$ & $3 \cdot 6$ & $5 \cdot 1^{y}$ & $3 \cdot 7$ & $11 \cdot 5^{\mathrm{b}}$ & $8 \cdot 7$ & $6 \cdot 3^{y}$ & 3.6 & $29 \cdot 6^{\star \star \star}$ & $14 \cdot 1^{\star \star \star *}$ \\
\hline Convenience foods & $0 \cdot 9^{\mathrm{a}}$ & $1 \cdot \overline{8}$ & $0 \cdot 5^{\mathrm{x}}$ & $1 \cdot 1$ & $1 \cdot 6^{b}$ & $2 \cdot 0$ & $1 \cdot 1^{y}$ & $1 \cdot 8$ & $7 \cdot 8^{\mathrm{c}}$ & $12 \cdot 7$ & $2 \cdot 2^{z}$ & 3.9 & $72 \cdot 0^{\star \star \star}$ & $20 \cdot 9^{\star \star \star}$ \\
\hline Fruit & $20 \cdot 2^{a}$ & $6 \cdot 9$ & $20 \cdot 1^{x}$ & $7 \cdot 2$ & $6 \cdot 9^{\mathrm{b}}$ & $5 \cdot 3$ & $8 \cdot 3^{y}$ & 4.9 & $6 \cdot 2^{\mathrm{b}}$ & 5.9 & $8 \cdot 2^{y}$ & $7 \cdot 4$ & $318 \cdot 1^{\star \star \star}$ & $506 \cdot 2^{\star \star \star}$ \\
\hline Vegetables & $27 \cdot 7^{\mathrm{a}}$ & $14 \cdot 8$ & $28 \cdot 7^{x}$ & $13 \cdot 0$ & $16 \cdot 7^{\mathrm{b}}$ & $8 \cdot 6$ & $18 \cdot 2^{y}$ & $8 \cdot 5$ & $13 \cdot 5^{\mathrm{b}}$ & $9 \cdot 6$ & $15 \cdot 2^{y}$ & $9 \cdot 9$ & $74 \cdot 7^{\star \star \star}$ & $135 \cdot 2^{\star \star \star}$ \\
\hline
\end{tabular}

Only high-frequency snack consumers (7.5-20.1 snack occasions/week) were included in the cluster analysis $(n 1890)$. Mean values indicate consumption frequency per week.

$a, b, c, x, y, z$ One-way ANOVA were used for examining differences between clusters $(P<0.001)$. Analysis was done for males and females separately. Mean values within rows with unlike superscript letters were significantly different (post hoc test: Tukey's Honestly Significant Difference test, $P<0 \cdot 05$ ): ${ }^{a}, b$, c for significant differences between clusters for males; ${ }^{*, y, y}, \mathrm{f}$ for significant differences between clusters for females.

${ }^{\star} P<0 \cdot 001$.

Table 6 Descriptive factors for the three clusters; presented for males and females separately: Swiss adults, 2010 (Swiss Food Panel)

\begin{tabular}{|c|c|c|c|c|c|c|c|c|c|c|c|c|c|c|c|c|}
\hline \multirow[b]{3}{*}{ Descriptive factor } & \multicolumn{4}{|c|}{ Cluster 1: 'Healthy' } & \multicolumn{4}{|c|}{ Cluster 2: 'Moderate' } & \multicolumn{4}{|c|}{ Cluster 3: 'Unhealthy' } & \multirow{2}{*}{\multicolumn{2}{|c|}{ Males }} & \multirow{2}{*}{\multicolumn{2}{|c|}{ Females }} \\
\hline & \multicolumn{2}{|l|}{ Males } & \multicolumn{2}{|c|}{ Females } & \multicolumn{2}{|l|}{ Males } & \multicolumn{2}{|c|}{ Females } & \multicolumn{2}{|l|}{ Males } & \multicolumn{2}{|c|}{ Females } & & & & \\
\hline & Mean or $\%$ & SD & Mean or $\%$ & SD & Mean or \% & SD & Mean or $\%$ & SD & Mean or $\%$ & SD & Mean or $\%$ & SD & $F$ or $\chi^{2}$ & $\mathrm{df}_{1}, \mathrm{df}_{2}$ or $\mathrm{df}$ & $F$ or $\chi^{2}$ & $\mathrm{df}_{1}, \mathrm{df}_{2}$ or $\mathrm{df}$ \\
\hline Age (years) & $53 \cdot 3^{\mathrm{a}}$ & $13 \cdot 0$ & $48 \cdot 2^{x}$ & 13.5 & $47 \cdot 8$ & $13 \cdot 6$ & $45 \cdot 6^{\mathrm{x}}$ & $13 \cdot 6$ & $47 \cdot 6^{\mathrm{b}}$ & $16 \cdot 4$ & $37 \cdot 9^{y}$ & $10 \cdot 8$ & $4 \cdot 2^{\star}$ & $2,759+$ & $8 \cdot 6^{\star \star \star}$ & $2,1115+$ \\
\hline Health consciousness & $4 \cdot 6^{\mathrm{a}}$ & 0.9 & $4 \cdot 9^{\mathrm{a}}$ & 0.8 & $4 \cdot 2^{\mathrm{b}}$ & $1 \cdot 0$ & $4 \cdot 5^{\mathrm{b}}$ & 1.0 & $3 \cdot 7^{\mathrm{c}}$ & $1 \cdot 1$ & $4 \cdot 2^{\mathrm{b}}$ & 0.9 & $16 \cdot 8^{\star \star \star}$ & $2,757 \dagger$ & $24 \cdot 1^{\star \star \star}$ & $2,1112 \dagger$ \\
\hline Wine and beer consumption frequency per week & $2 \cdot 8^{\mathrm{a}}$ & 3.3 & $1 \cdot 2^{x, y}$ & $2 \cdot 1$ & $2 \cdot 8^{\mathrm{a}}$ & 3.3 & $1 \cdot 4^{\mathrm{x}}$ & $2 \cdot 1$ & $4 \cdot 8^{\mathrm{b}}$ & $7 \cdot 1$ & $0.4^{y}$ & 0.6 & $6 \cdot 9^{\star \star}$ & $2,759+$ & $3 \cdot 8^{*}$ & $2,1123+$ \\
\hline BMI $\left(\mathrm{kg} / \mathrm{m}^{2}\right)$ & $25 \cdot 3$ & $3 \cdot 4$ & $23 \cdot 1$ & $4 \cdot 1$ & $25 \cdot 5$ & 3.6 & $23 \cdot 4$ & $4 \cdot 4$ & 24.5 & $3 \cdot 6$ & $22 \cdot 1$ & 3.3 & $1 \cdot 7^{\mathrm{NS}}$ & $2,757 \dagger$ & $1 \cdot 6^{\mathrm{NS}}$ & $2,1110+$ \\
\hline Overweight (\%) & 47.6 & - & $23 \cdot 2$ & - & $47 \cdot 8$ & - & $24 \cdot 7$ & - & $46 \cdot 2$ & - & $18 \cdot 8$ & - & $0.1^{\mathrm{NS}}$ & 2 & $0.9^{\mathrm{NS}}$ & 2 \\
\hline Physical activity $\geq 30 \mathrm{~min} / \mathrm{d}(\%)$ & 68.6 & - & $63 \cdot 7$ & - & $64 \cdot 4$ & - & $52 \cdot 1$ & - & 68.9 & - & $58 \cdot 6$ & - & $3 \cdot 3^{\mathrm{NS}}$ & 2 & $10 \cdot 9^{\star \star}$ & 2 \\
\hline Having children $\leq 16$ years old (\%) & $29 \cdot 0$ & - & $33 \cdot 6$ & - & $27 \cdot 7$ & - & 39.9 & - & $22 \cdot 4$ & - & $45 \cdot 5$ & - & $1 \cdot 0^{\mathrm{NS}}$ & 2 & $4.5^{\mathrm{NS}}$ & 2 \\
\hline Family meals $4-7$ times/week (\%) & 64.8 & - & 63.7 & - & 62.6 & - & $68 \cdot 2$ & - & 55.8 & - & 75.8 & - & $2 \cdot 3^{\mathrm{NS}}$ & 2 & $3 \cdot 0^{\mathrm{NS}}$ & 2 \\
\hline Watching TV during the main meal $4-7$ times/week (\%) & $10 \cdot 2$ & - & 13.5 & - & $15 \cdot 2$ & - & $15 \cdot 7$ & - & 30.6 & - & 33.3 & - & $12 \cdot 3^{\star \star}$ & 2 & $8 \cdot 9^{\star}$ & 2 \\
\hline Daily breakfast (\%) & $70 \cdot 4$ & - & 73.7 & - & $52 \cdot 6$ & - & $59 \cdot 5$ & - & $44 \cdot 2$ & - & 33.3 & - & $11 \cdot 3^{\star \star}$ & 2 & $26 \cdot 8^{\star \star \star}$ & 2 \\
\hline Daily lunch $(\%)$ & $74 \cdot 7$ & - & $79 \cdot 8$ & - & $66 \cdot 9$ & - & $75 \cdot 1$ & - & $69 \cdot 2$ & - & $75 \cdot 8$ & - & $0 \cdot 1^{\mathrm{NS}}$ & 2 & $7 \cdot 2^{*}$ & 2 \\
\hline Daily dinner (\%) & 86.5 & - & 85.5 & - & $77 \cdot 8$ & - & $81 \cdot 6$ & - & 74.5 & - & 90.9 & - & $2 \cdot 6^{\mathrm{NS}}$ & 2 & $6 \cdot 0^{\star}$ & 2 \\
\hline \multicolumn{17}{|l|}{ Education (\%) } \\
\hline Low & $7 \cdot 5$ & - & $10 \cdot 2$ & - & 8.3 & - & $11 \cdot 1$ & - & $17 \cdot 3$ & - & $12 \cdot 1$ & - & $13 \cdot 7^{\star \star}$ & 4 & $5 \cdot 6^{\mathrm{NS}}$ & 4 \\
\hline Middle & 37.3 & - & 37.7 & - & 37.9 & - & $42 \cdot 1$ & - & 51.9 & - & 54.5 & - & & & & \\
\hline High & $55 \cdot 2$ & - & $52 \cdot 1$ & - & $53 \cdot 7$ & - & $46 \cdot 8$ & - & $30 \cdot 8$ & - & $33 \cdot 3$ & - & & & & \\
\hline
\end{tabular}

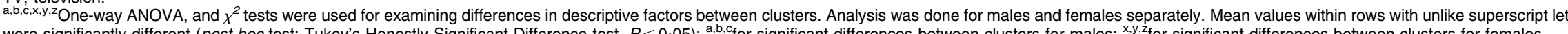

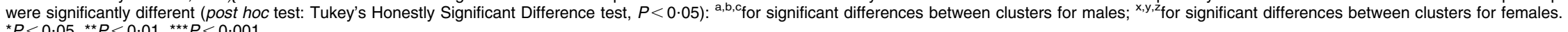

+Values are indicated as $\mathrm{df}_{1}, \mathrm{df}_{2}$. 
consumption frequency scores from the questionnaire might be biased by conscious or unconscious under/ over-reporting of true food consumption ${ }^{(29)}$. Additionally, in the case where respondents indicated a recent change to their nutrition pattern, the cross-sectional design made it impossible to differentiate between whether their actual body weight status was a cause or a consequence of their reported nutritional pattern. BMI was calculated from selfreported weight and height. Thus, an underestimation/ under-reporting of weight was likely to occur, particularly among overweight and obese respondents ${ }^{(30)}$.

In general, FFQ are used most often in studies with large sample sizes, to estimate individuals' habitual food intake ${ }^{(31)}$. Nevertheless, they give only limited information about individuals' food intake and they do not capture dietary behaviour in its entirety.

Interpretation of snack frequency per week might have been biased by the fact that there are conflicting views held by the general public about the definition of a 'snack' and a 'meal'(32). Consumers conceptualise snacks differently - for example, using time of day or food type as a means of classification ${ }^{(32)}$. In particular, food intake close to main meal consumption might be classified either as part of the main meal or as snack, depending on individual views. Additionally, people practising a nontraditional mealtime pattern with more than four snack occasions per day, or with a so-called 'nibbling pattern', could not be clearly detected using this method.

Some studies do not control for physical activity, a possible confounder of the association between eating frequency and $\mathrm{BMI}^{(33)}$. Therefore, we interpreted physical activity of more than $30 \mathrm{~min} / \mathrm{d}$ to identify an active lifestyle. In our study, we did not find an association between snack frequency and physical activity. A possible limitation may be that we could not distinguish between different exercise intensities, which may influence snack frequency as well as energy balance, and thus body weight status. It should also be mentioned that the response rate was low and that the study population had significantly fewer lowereducated participants than higher-educated participants. This should be taken into consideration when the results are interpreted.

\section{Conclusion}

In our study, we measured snack frequency, which refers to the number of additional food items consumed between main meals. The results indicate that there is no association between BMI and snack frequency.

High-frequency snack consumption occurs in the context of healthy, as well as unhealthy, dietary behaviour and lifestyle patterns. Women are more likely to make healthier dietary food choices, while men are likely to choose unhealthy foods such as sweets and savouries more often. In developing prevention strategies or interventions, instead of advising a specific number of snacks per day, healthy food choices and healthy lifestyles should be stimulated. Advising a general increase in snack consumption might even have unfavourable effects, as increasing the number of eating occasions per day without increasing the energy intake at the same time might be difficult to achieve ${ }^{(34)}$. The consumption of nutritious snacks should be promoted and consumers, especially men, need to be sensitised to the energy density of sweets and savouries as snacks.

\section{Acknowledgements}

The Swiss Federal Office of Public Health funds the Swiss Food Panel. C.H. is supported by the Swiss Federal Office of Public Health. The authors declare no conflicts of interest for this study. M.S. and K.v.d.H. participated in the design of the study; C.H. and K.v.d.H. conducted the data analysis and wrote the manuscript; M.S. made critical comments on the drafts.

\section{References}

1. La Bounty Paul CB, Jacob W, Elfego G et al. (2011) International Society of Sports Nutrition position stand: meal frequency. J Int Soc Sports Nutr 8, 1-12.

2. Chiva M (1997) Cultural aspects of meals and meal frequency. BrJ Nutr 77, 21-28.

3. Hill JO \& Melanson EL (1999) Overview ot the determinants of overweight and obesity: current evidence and research issues. Med Sci Sports Exerc 31, 515-521.

4. Piernas C \& Popkin BM (2010) Snacking increased among US adults between 1977 and 2006. J Nutr 140, 325-332.

5. Hampl JS, Heaton CLB \& Taylor CA (2003) Snacking patterns influence energy and nutrient intakes but not body mass index. J Hum Nutr Diet 16, 3-11.

6. Johnson GH \& Anderson GH (2010) Snacking definitions: impact on interpretation of the literature and dietary recommendations. Crit Rev Food Sci 50, 848-871.

7. Holmback I, Ericson U, Gullberg B et al. (2010) A high eating frequency is associated with an overall healthy lifestyle in middle-aged men and women and reduced likelihood of general and central obesity in men. BrJ Nutr 104, 1065-1073.

8. Whybrow S \& Kirk TR (1997) Nutrient intakes and snacking frequency in female students. J Hum Nutr Diet 10, 237-244.

9. Mills JP, Perry CD \& Reicks M (2011) Eating frequency is associated with energy intake but not obesity in midlife women. Obesity (Silver Spring) 19, 552-559.

10. Leidy HJ \& Campbell WW (2011) The effect of eating frequency on appetite control and food intake: brief synopsis of controlled feeding studies. J Nutr 141, 154-157.

11. Schlundt DG, Hill JO, Sbrocco T et al. (1992) The role of breakfast in the treatment of obesity - a randomized clinical-trial. Am J Clin Nutr 55, 645-651.

12. Swinburn B, Egger G \& Raza F (1999) Dissecting obesogenic environments: the development and application of a framework for identifying and prioritizing environmental interventions for obesity. Prev Med 29, 563-570.

13. Berteus-Forslund H, Torgerson JS, Sjostrom L et al. (2005) Snacking frequency in relation to energy intake and food choices in obese men and women compared to a reference population. Int J Obes (Lond) 29, 711-719. 
14. Nielsen SJ, Siega-Riz AM \& Popkin BM (2002) Trends in energy intake in US between 1977 and 1996: similar shifts seen across age groups. Obes Res 10, 370-378.

15. Boutelle KN, Birnbaum AS, Lytle LA et al. (2003) Associations between perceived family meal environment and parent intake of fruit, vegetables, and fat. J Nutr Educ Behav 35, 24-29.

16. Coon KA, Goldberg J, Rogers BL et al. (2001) Relationships between use of television during meals and children's food consumption patterns. Pediatrics 107, e7.

17. Beer-Borst S, Hercberg S, Morabia A et al. (2000) Dietary patterns in six European populations: results from EURALIM, a collaborative European data harmonization and information campaign. Eur J Clin Nutr 54, 253-262.

18. Dynesen AW, Haraldsdottir J, Holm L et al. (2003) Sociodemographic differences in dietary habits described by food frequency questions results from Denmark. Eur J Clin Nutr 57, 1586-1597.

19. Whybrow S, Mayer C, Kirk TR et al. (2007) Effects of two weeks' mandatory snack consumption on energy intake and energy balance. Obesity (Silver Spring) 15, 673-685.

20. Swiss Federal Statistical Office (2010) Population and Household statistics (STATPOP). http://www.bfs.admin.ch/ bfs/portal/de/index/infothek/erhebungen_quellen/blank/ blank/statpop/01.html (accessed April 2011).

21. Hu FB \& Malik VS (2010) Sugar-sweetened beverages and risk of obesity and type 2 diabetes: epidemiologic evidence. Physiol Behav 100, 47-54.

22. van der Horst K, Brunner TA \& Siegrist M (2010) Readymeal consumption: associations with weight status and cooking skills. Public Health Nutr 14, 239-245.

23. Faramawi MF, Johnson E, Fry MW et al. (2007) Consumption of different types of meat and the risk of renal cancer: meta-analysis of case-control studies. Cancer Causes Control 18, 125-133.
24. Schifferstein HNJ \& Oude Ophuis PAM (1998) Healthrelated determinants of organic food consumption in the Netherlands. Food Qual Prefer 9, 119-133.

25. Gould SJ (1990) Health consciousness and health behavior the application of a new health consciousness scale. Am J Prev Med 6, 228-237.

26. Wardle J, Haase AM, Steptoe A et al. (2004) Gender differences in food choice: the contribution of health beliefs and dieting. Ann Behav Med 27, 107-116.

27. Fagerli RA \& Wandel M (1999) Gender differences in opinions and practices with regard to a 'healthy diet'. Appetite 32, 171-190.

28. Haveman-Nies A, de Groot LPGM \& van Staveren WA (1998) Snack patterns of older Europeans. J Am Diet Assoc 98, 1297-1302.

29. Voss S, Kroke A, KlipsteinGrobusch K et al. (1997) Obesity as a major determinant of underreporting in a selfadministered food frequency questionnaire: results from the EPIC-Potsdam study. Z Ernabrungswiss 36, 229-236.

30. Nyholm M, Gullberg B, Merlo J et al. (2007) The validity of obesity based on self-reported weight and height: implications for population studies. Obesity (Silver Spring) 15, 197-197.

31. Cade J, Thompson R, Burley V et al. (2002) Development, validation and utilisation of food-frequency questionnaires a review. Public Health Nutr 5, 567-587.

32. Gatenby SJ (1997) Eating frequency: methodological and dietary aspects. Br J Nutr 77, 7-20.

33. Duval K, Doucet E, Strychar I et al. (2008) Physical activity is a confounding factor of the relation between eating frequency and body composition. Am J Clin Nutr 88, 1200-1205.

34. Forslund HB, Lindroos AK, Sjostrom L et al. (2002) Meal patterns and obesity in Swedish women - a simple instrument describing usual meal types, frequency and temporal distribution. Eur J Clin Nutr 56, 740-747. 